\title{
Memorias de la dictadura en el arte tecnológico: el Mundial de 1978
}

\author{
Memories of dictatorship in technological art: 1978 World Cup
}

\author{
Nadia Martin martin.nadia@gmail.com \\ https://orcid.org/0000-0001-9650-9976 \\ Instituto de Investigación en Arte y Cultura Dr. Norberto Griffa; Universidad de Tres de Febrero/ \\ Consejo Nacional de Investigaciones Científicas y Técnicas (Argentina)
}

\section{Resumen}

Este trabajo considera dos obras de arte tecnológico contemporáneo que recurren al Mundial de fútbol de 1978 disputado en Argentina como terreno de exploración estética y conceptual: Desiluciones Ópticas (2013), de Leo Núñez y 1978-2003 (2003), de Carlos Trilnick. Para su análisis, se recuperan estudios sobre comunicación mediática en el contexto de la dictadura, con foco en la transmisión del evento deportivo; algunos antecedentes sobre las políticas de la memoria en la Argentina; y algunos trazados contextuales sobre el vínculo (histórico y teórico) entre arte y memoria. Desde este cruce, se observa que estas dos producciones artísticotecnológicas participan de procesos contemporáneos de memoria del pasado dictatorial, en los que es posible observar una relectura crítica, por un lado, del rol de la sociedad civil (de víctima 
inocente a agente responsable); y por el otro, del discurso de los medios de comunicación (y sus estrategias de manipulación y legitimación del régimen).

Palabras clave: Mundial 1978; memoria; arte tecnológico.

\section{Abstract}

This paper accounts two works of contemporary technological art that considers 1978 World Cup played in Argentina as a territory for their aesthetic and conceptual exploration: Desiluciones Ópticas (2013), by Leo Núñez and 1978-2003 (2003), by Carlos Trilnick. For the analysis, there are some fields of knowledge wich are recoverred: some researchs on media communication in the context of dictatorship, with special attention to those which focuss on the transmission of the sporting event; some background on the policies of memory in Argentina; and some contextual itineraries on the relationship (historical and theoretical) between art and memory. From this intersection, it is observed that these two artistic-technological productions participate in contemporary memory processes about the dictatorial past, in which it is possible to recognize a critical rereading, on the one hand, of civil society's role (from innocent victim to responsible agent); and on the other hand, of media's discourse (their strategies of manipulation and legitimacy of the regime).

Keywords: 1978 World Cup; memory; technological art.

El vínculo entre las funciones del arte y los procesos de memoria referidos a la última dictadura cívico-militar consiste en un nudo problemático extensamente trabajado en las últimas décadas. No obstante, han sido escasos los intentos de abordarlo considerando las producciones tecnopoéticas contemporáneas. Asimismo, el Mundial de fútbol de 1978 (y la complicidad mediática para construir la imagen pública de un país en orden), ha sido analizado desde los estudios en comunicación, sociológicos e históricos, pero escasamente utilizado como terreno de exploración estética.

Considerando tal estado de situación, este trabajo ensaya una propuesta de análisis de una obra low-tech y otra de video que abordan la desaparición de personas en el contexto del Mundial del 78. Se trata de obras que utilizan como materia de expresión los mismos dispositivos técnicos y mediáticos que cuestionan. En su propuesta, se sitúan como prácticas de denuncia y señalización respecto del rol de los medios de comunicación, a la vez que discuten la presunción de inocencia por desconocimiento por parte de la sociedad civil. 
A lo largo del análisis, se recuperan algunos trayectos sobre el vínculo (histórico y teórico) entre arte y memoria, como asimismo algunos antecedentes sobre las políticas de la memoria en la argentina -y el peso del marco jurídico con el cual las mismas fueron estructuradas en los primeros años de democracia-. También se reponen algunos estudios que contextualizan cómo se mediatizó el evento de fútbol y cómo el aparato dictatorial hizo un uso político del mismo. En el cruce entre estos campos del conocimiento, se entiende que estos trabajos permiten observar algunos aspectos del modo en que la contemporaneidad recuerda críticamente y resignifica la memoria del Mundial de fútbol; en particular, las redes de complicidades generadas por los medios de comunicación y la sociedad civil, que vivió una de sus mayores alegrías populares en medio del estado de excepción impuesto por el terrorismo de Estado.

\section{Trayectos preliminares en arte y memoria}

El ámbito de la cultura y más específicamente de la representación artística ha funcionado, desde el inicio de la dictadura, como terreno idóneo para movilizar la sensibilidad política, denunciar -abierta o lateralmente- el dispositivo de terror y trabajar, asimismo, el duelo colectivo. Sin embargo, es en 2003/2004 cuando, restablecido el orden luego de la crisis institucional, económica y social más grande de la historia democrática del país, comenzará un período de sistematización de las políticas de la memoria, tal y como dan cuenta -entre otrosen el Informe sobre Derechos Humanos en la Argentina del Centro de Estudios Legales y Sociales (CELS, https://www.cels.org.ar/web/) de 2016 y el informe de Políticas Públicas de Verdad y Justicia en la Argentina de la Universidad de Chile de 2001. En tal contexto, en el que se da una significativa proliferación de obras y muestras de artes visuales abocadas a la temática, resulta llamativa la escasez de iniciativas generadas desde el circuito del arte tecnológico. Al respecto, cabe aludir dos muestras organizadas por la Universidad Nacional de Tres de Febrero (UNTREF) (en 2006 y 2016 respectivamente) y curadas por Gabriela Golder y Andrés Denegri, ambas nombradas "Ejercicios de Memoria" (1). Estas muestras proponían reflexionar sobre las memorias de pasados recientes desde ejercicios tecnopoéticos (obras de video, instalaciones interactivas, esculturas robóticas, instalaciones electroacústicas). En la primera versión de esta muestra, se expusieron las dos obras que aquí se analizan.

Por otro lado, resulta oportuno destacar que en los activismos artísticos y el arte político existe una insistente utilización de matrices de representación relativamente cristalizadas en la memoria colectiva. Las tecnopoéticas contemporáneas, también las recuperan. Entre ellas, se encuentran las fotos y las siluetas, que según distingue Ana Longoni (2010), son las dos

Question, Vol. 1, N. ${ }^{\circ}$ 63, julio-septiembre 2019. ISSN 1669-6581

Instituto de Investigaciones en Comunicación | Facultad de Periodismo y Comunicación Social | Universidad Nacional de La Plata 
principales estrategias creativas generadas por el movimiento de Derechos Humanos para la representación del desaparecido. Las instalaciones Rostros y Desiluciones Ópticas de Leo Núñez utilizan retratos de desaparecidos; el uso figural de las siluetas, por su parte, aparece en obras de video como Diez hombres sólos de Ar Detroy o Como un cuerpo ausente, de Carlos Trilnick. Otra estrategia insistentemente trabajada en campo del arte y la memoria, la del testimonio del sobreviviente, es tematizado también en obras de video monocanal como Granada de Graciela Taquini o De lo de adentro de Ana Gallardo. Sin embargo, el Mundial de fútbol de 1978 (y la complicidad mediática para construir la imagen de un país en orden), es un terreno extensamente analizado desde los estudios en comunicación, sociológicos e históricos, pero apenas advertido como espacio de exploración estética.

Dicho esto, resulta menester referir a dos muestras recientes que, con motivo de los 40 años del Mundial del 78 y en paralelo al Mundial de Rusia de 2018, se realizaron en la Ciudad de Buenos Aires: Tiren Papelitos, curada por Florencia Battiti en el Parque de la Memoria, y El mundial en la ESMA, realizada en tal ex-institución. Mientras esta última recogía la experiencia del Mundial de 1978 desde la perspectiva de los sobrevivientes de la ESMA (entre otras, mediante la reconstrucción de eventos que daban cuenta de la cruenta contradicción entre el júbilo popular y el horror vivido por los prisioneros), en Tiren Papelitos se reconstruía el contexto mediante archivo de archivos de prensa escrita, humor gráfico y video documentales, pero también se recurría a cuatro obras de arte. Entre ellas, se incluía el video de Carlos Trilnick que se trabaja en este artículo.

Comentados tales antecedentes, el Mundial del 78 se trata entonces de un motivo que tendría la potencia de abrir los modos habituales con los que se organizan las poéticas de la memoria, a problemáticas escasamente trabajadas desde el terreno específico del arte, y aún menos del tecnológico. Mediante la estrategia visual de referir al contexto del campeonato de fútbol, estas obras se abocan primordialmente a una crítica a la connivencia de la sociedad civil y al uso manipulatorio que el poder mediático hizo del evento. En este sentido, se las puede comprender como producciones de una contemporaneidad en la que algunos sentidos históricos arraigados en el sentido común (vinculados a la denominada teoría de los dos demonios y la idea de una sociedad civil inocente cuando no mera víctima por desconocimiento) son puestos en revisión.

\section{El Mundial del 78}


La organización del mundial de fútbol fue concedida a la argentina en 1966; es decir, la Junta Militar que tomó el poder en 1976 heredó este compromiso de la dictadura de Onganía. Sin embargo, pocas semanas después del golpe, el evento se convirtió en una prioridad: se intervino el Ente Autárquico del Mundial (EAM) y se iniciaron obras de infraestructura y acondicionamiento (incluidas la modernización de ciudades y construcción de estadios) que implicaron inversiones millonarias (Archetti, 2004). La Junta sabrá hacer un uso político muy oportuno del evento.

El año 1978 encuentra a la dictadura en un contexto de presiones y denuncias internacionales por la violación sistemática de los derechos humanos, a lo que se sumaban índices económicos lejanos a resultar alentadores y una sociedad civil aplanada por su imposibilidad de reunirse y expresarse libremente. En un país culturalmente atravesado por la pasión por el fútbol, el desarrollo del evento consistía en una estrategia para elevar el estado de ánimo, simular la legitimidad del régimen y construir consenso. De este modo, se aprovechó la movilización de pasiones y multitudes para contrarrestar lo que la Junta acusaba de ser una "campaña antiargentina" perpetuada desde el extranjero (Varela, 2001) (2).

Como indica Mirta Varela (2001), la censura no se instala de pronto y de plano con el Golpe. Desde hacía más de un cuarto de siglo, y con especial acentuación desde 1974, existían condiciones de reglamentación y de funcionamiento institucional de los medios de comunicación que indicaban un signo censor, y las Juntas luego hicieron un uso indiscriminado de ellas. No obstante estas tendencias preexistentes, el Comunicado Nro. 19 de 1976 suprime la libertad de prensa, instalando una fuerte presión sobre los medios. Las dos primeras semanas del régimen militar establecerán las condiciones con las que las Juntas librarán su "guerra ideológica" (Avellanera, 1986: 10), en la que los medios masivos jugarán un papel fundamental; particularmente la prensa, la televisión y el cine. De esta forma, el período dictatorial, con particular énfasis en la etapa que se extiende entre 1976 y 1980, estará marcado por la presión ideológica, la persecución y la censura (devenida pronto en autocensura y complicidad), como así también por un discurso altamente monolítico en lo que respecta a la difusión de lo que el gobierno de facto enaltecía como valores primordiales: el orden institucional, la laboriosidad, el respecto a autoridad, la honestidad, la moral cristiana, entre otros (Varela, 2001).

Son estos mismos valores los que el evento deportivo, mediatizado, hará circular. Según muestran numerosos estudios (Varela, 2001; Franco, 2007; Borrelli, 2011) la organización del campeonato sirvió como aparato propagandístico y, en este rol, los medios y particularmente la prensa gráfica fueron legitimadores activos de los argumentos oficiales que exaltaban la unidad nacional, la nobleza de los ciudadanos y la normalidad que la argentina había restablecido 
gracias al Golpe de Estado. Desde la radio y la televisión, por su parte, se promovieron los festejos callejeros como modo de mostrar al mundo la alegría popular; los relatos de los partidos estuvieron plagados de entusiasmo nacionalista $y$, a la vez, el "triunfo" de la organización y del equipo eran equiparados con el triunfo del gobierno y de la nación, aportando al establecimiento de un consenso sobre la bienaventuranza de la dictadura (3).

Así pues, el mundial presenta un dilema irresoluble: el de una genuina pasión por el fútbol que hasta las víctimas directas del régimen declaran haber compartido (4), en el contexto de uno de los momentos más crueles de nuestra historia. Se trata de una situación ambivalente, contradictoria, en la que se chocan tensiones de diversos niveles: medios de comunicación que funcionaban entre el amordazamiento y la complicidad, una sociedad civil que vivía en el filo entre la ignorancia y la negación, la existencia de una pasión popular trenzada a un oportuno chauvinismo nacionalista.

De esta forma, el campeonato -como espacio donde volver a observar las complejidades del terrorismo de estado (sobre todo, en lo que respecta a las articulaciones entre vida cotidiana, estrategias del poder disciplinar/represor y funcionamiento mediático)- consiste también en una estrategia de representación del terror dictatorial que es utilizada en el arte tecnológico contemporáneo.

\section{Desilusiones ópticas}

Desilusiones ópticas es una instalación reactiva creada en 2013 por Leo Núñez. La misma consiste en un ambiente oscuro, sin ningún tipo de decorado, en cuyo piso se encuentra dispuesta, para que el público los arroje al aire, una pila de trozos de papel de diario y guías telefónicas, cortadas a mano. El audio reproduce una hinchada de fútbol. El dispositivo técnico (oculto en el emplazamiento) consta de un sensor Kinect que capta el movimiento. Un software ( $\mathrm{C}_{++}$y shaders) diseñado ad hoc reconoce el vuelo de los papeles y su posición en el espacio y genera una imagen lumínica (un crisol de retratos de desaparecidos) que se proyecta en ellos (5). El espectador es embestido así con la sobreimpresión de estos rostros sobre el acto y el material de la celebración.

Según han analizado detalladamente Ludmila Da Silva Catela (2009), Claudia Feld (2010) y Ana Longoni (2010), entre otros, en el comienzo de la dictadura las Madres recurrieron a las fotos de sus hijos para iniciar una búsqueda sin éxito en comisarías, hospitales y otras instituciones. Pronto las empezaron a llevar a las rondas de los jueves, colgadas de sus cuerpos o incorporándolos a pequeños carteles. Rápidamente, el recurso se socializará y 
calará hondo en la memoria colectiva. Las fotos eran extraídas del álbum familiar o consistían en ampliaciones de la foto-carnet de los documentos de identidad, y poseían un valor probatorio que remitía a la vida efectiva de personas con una biografía previa al secuestro. En este caso, el dispositivo visual del mundial se articula con el uso figural del retrato del desaparecido sobre el mero gesto celebratorio. Se introduce, así, en el presente del espectador un elemento ajeno, heterocrónico (un conjunto de fotografías del pasado), que por asociación lo ubica de pronto en 1978. La obra pone en escena entonces a otra temporalidad: un pasado desaparecedor vuelto presente, que aparece tamizado por una perspectiva actual de repudio, codificada en una imagen que porta en sí misma décadas de lucha.

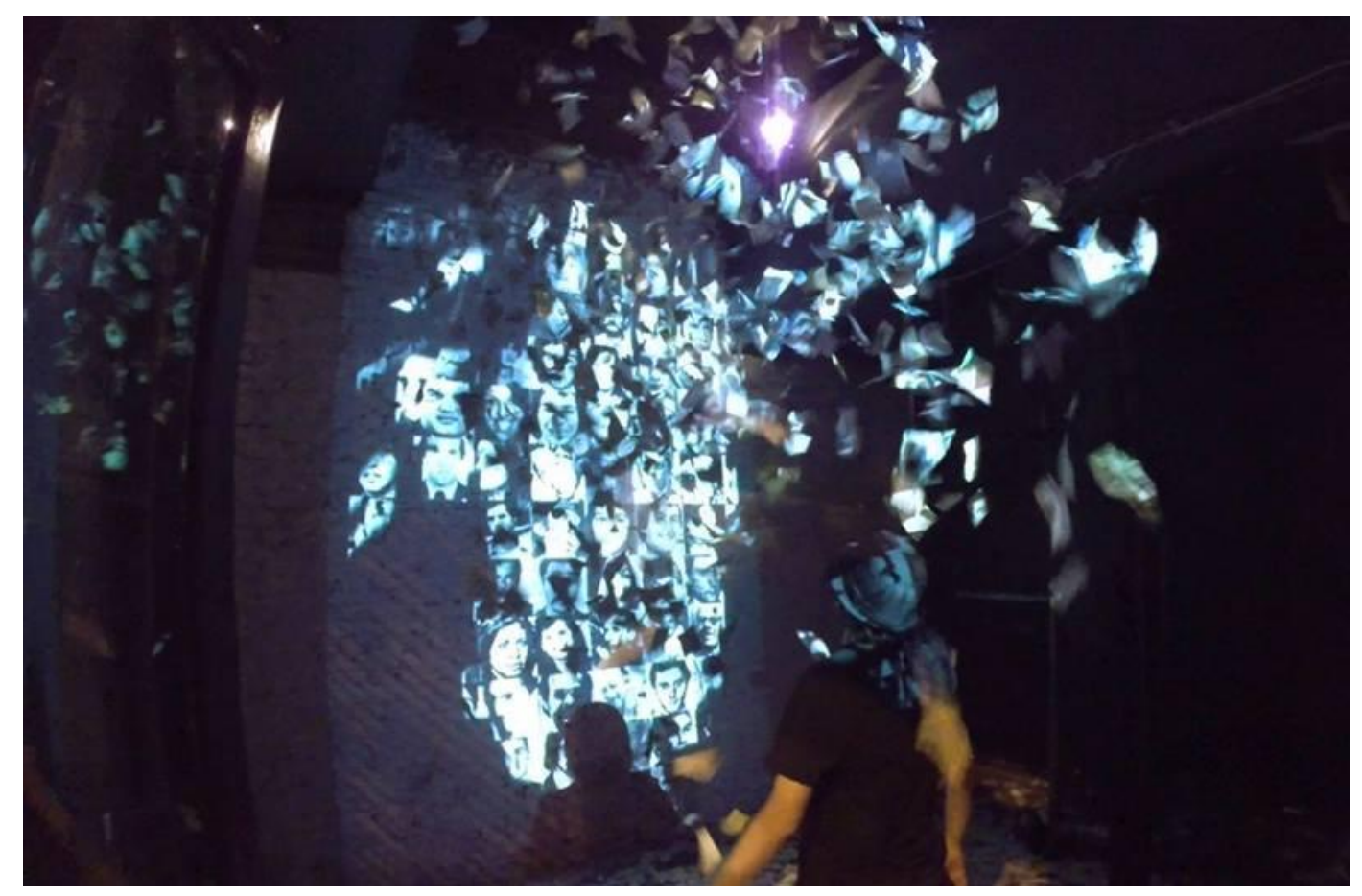

Núñez, L. (2013). Desilusiones ópticas. Imagen cortesía del artista.

En la obra es posible observar la construcción de un enunciatario dicotómico, dividido. Por un lado, pareciera reconocerlo como una víctima inocente de la manipulación: tanto el dispositivo represor y mediático de la dictadura como el dispositivo técnico de la obra, operan desde el ocultamiento de información. De esta forma, un lado oculto de la obra (y, por alusión, de la realidad) se revela cuando ya es demasiado tarde, cuando el espectador ya ha participado de los festejos del mundial -tanto en el evento real del 78 como en el recreado desde el presentede forma ingenua. Pero con este mismo artilugio, la obra pareciera también señalar al 
espectador cierta realidad culposa que lo insta a reconocerse en la memoria vergonzosa del gesto celebratorio; en la posibilidad de observarse cómplice del horror, por ingenuidad o distracción.

De esta forma, en Desilusiones ópticas, el mundial de fútbol funciona como emplazamiento, como escenario en el que se enmarca una experiencia reflexiva acerca la lógica siniestra del ocultamiento sistemático de la verdad (y como parte de ella, de los cuerpos) que remite a la complicidad mediática. Algo de esta obra remite a los collages Nosotros no sabíamos que León Ferrari produce desde el exilio en Brasil: no sólo porque también trabajaba con papeles de diarios, sino porque en sus recortes de notas en los que las desapariciones eran efectivamente comunicadas, el célebre artista dejaba expuesta a una sociedad civil apática, a la vez que desarticulaba su extendida presunción de inocencia. La obra de Núñez reactualiza en parte este sentido y sorprende al espectador repitiendo la historia: propone así ejercitar lúdica y activamente la actitud crítica, complejizar la memoria admitiendo cierta responsabilidad de la sociedad civil durante el régimen.

1978-2003

Realizada en 2003, 1978-2003 de Carlos Trilnick surge como parte de un proyecto televisivo organizado por el Canal de la Ciudad, en el que se invitó a cien artistas a realizar un plano de la Ciudad de Buenos Aires. Sin embargo, en un texto crítico de esta obra que se publica tanto en el catálogo de la Muestra Ejercicios de Memoria 1 como un libro-catálogo retrospectivo del artista compilado por Jorge la Ferla, ambos editados en 2007, Andrés Denegri destaca que

Trilnick no hizo TV, esta pieza es un video en la televisión, una intervención en el flujo televisivo. Logra que la cámara vuelva donde estuvo veinticinco años antes y no pudo ver. Al desplegar su tela negra, pone en imagen la antes invisible venda en los ojos (2007: 147).

La pieza consiste en una toma fija de un arco de la cancha de River Plate, captado a la distancia de un plano general y con sonido directo. En su versión instalativa (6), sus siete minutos de duración son proyectados en loop sobre una superficie de $4 \times 3$ metros. El estadio donde se desarrolló la final del campeonato Mundial de Fútbol de 1978, se observa completamente vacío, con el rozamiento del viento como protagonista del sonido ambiente. Del margen inferior derecho del cuadro, emerge un hombre sólo, vestido de negro que, de espaldas a la cámara, camina hasta el arco con un paño negro entre sus brazos. Al llegar a la 
meta, ata la tela a los extremos. Con este gesto consumado, se retira: camina de frente hacia la cámara hasta salir de cuadro.

Ya en Por qué pintar un cuadro negro, de 2002, el propio Trilnick cubría con un velo negro el espacio abierto entre dos troncos de árboles pelados. En este caso, el mismo concepto de video performático se retoma para velar el arco sobre el que se marcaron los goles que llevaron al triunfo de la selección en tiempos en los que él mismo se encontraba en el exilio en Israel. Su intervención cubre al sitio con el negro del luto, silencia -incluso impide- todo intento de festejo. La sobreimpresión con la que inicia el video no deja dudas de la severidad de la propuesta; en la misma se lee: "en homenaje a los desaparecidos durante el mundial de fútbol Argentina 78 organizado en este estadio por la dictadura militar".
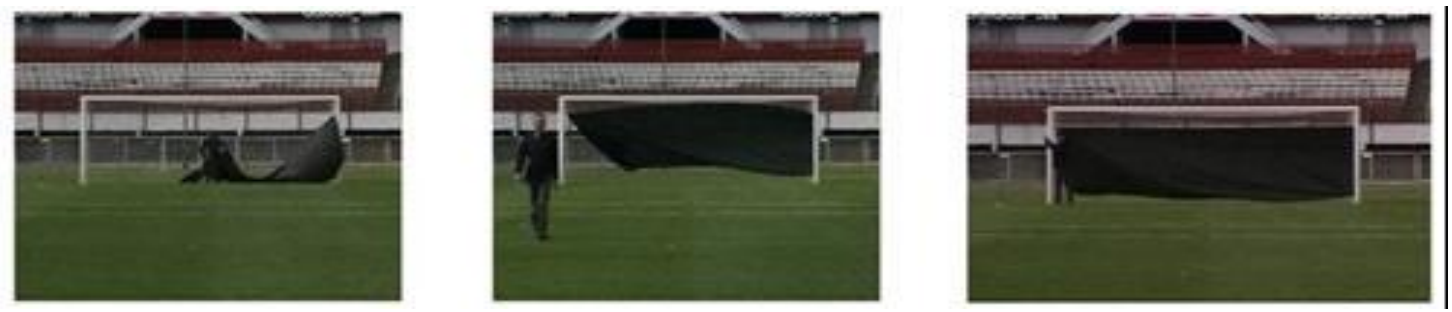

Trilnick, C. (2003). 1978-2003. Imagen: captura del video.

Sin embargo, el video no se limita a registrar un gesto de repudio en el campo de juego, sino que a nivel del tratamiento formal y mediático de la imágen dispara otras líneas de sentido: la toma fija, sin ningún tipo de estrategia de posproducción, desvirtúa los modos habituales del lenguaje televisivo. La captura de la imagen sin cortes, sin cambios de ángulos ni de encuadre, sin sobreimpresiones ni trasparencias, sin música ni efectos de sonido, discute la lógica del fragmento, de la edición y del montaje que, tal y como dan cuenta numerosos especialistas (Dubois, 2001; Machado, 2000; La Ferla, 2000; 2009) caracteriza a los medios audiovisuales. El gesto niega simbólicamente no sólo la victoria del equipo sino también la del espectáculo mediatizado. Señala su renuncia a las estrategias hegemónicas de tratamiento de la imagen. Mirta Varela indica respecto de la transmisión mediática del evento:

Durante el campeonato, tanto desde la televisión como desde la radio, se promovió el festejo callejero -como modo de 'mostrar al mundo' el clima de 'alegría popular'- (...) El locutor José María Muñoz se convirtió en la voz más representativa de este evento (...). Las imágenes de la inauguración: infinidad de palomas soltadas al aire, así como los esquemas gimnásticos de una rutina fuertemente militarizada, o la conjunción entre el festejo y el rostro del general Videla, 
son imágenes captadas por la televisión que se volvieron representativas de este evento y de las contradicciones que este festejo ponía en escena en la sociedad (Varela, 2001: 57).

De esta forma, ante los registros de ATC que exhiben un equipo triunfante y un pueblo enardecido al grito de los goles, ante la película oficial del mundial en la que se destaca a un Videla que alza sus brazos de protagonista desde el palco (7), Trilnick opta por una operación formal mínima, despojada de artilugios y pasiones. Genera una imagen disidente que organiza, en sí misma, una mirada crítica sobre los modos de mediatizar la cancha de juego. En este sentido, subyace a la obra no sólo una crítica a la complicidad mediática, sino también cierta repulsa al supuesto desconocimiento de la sociedad civil: la obra señala el sitio donde el pueblo se distraía y festejaba, mientras a pocos metros en la Escuela de Mecánica de la Armada (ESMA) se llevan a cabo las peores atrocidades (8). Y con este mismo señalamiento, la instalación también practica una modalidad del site specific: el estadio, en este caso, se exhibe como espacio de contemplación silente, reflexiva. Se lo redimensiona, así, como sitio de memoria.

\section{Potenciales de apertura}

Llegados a esta instancia, resulta oportuno destacar que desde el retorno de la democracia, las políticas de la memoria en la Argentina estuvieron ancladas a una suerte de pacto ideológicopolítico sostenido por el temor a la repetición de lo acontecido y por la demanda de justicia, que tomó forma bajo un reclamo de juricidad:

En esos tiempos iniciales de la postdictadura, la recuperación de un contenido ético para la democracia, la revaloración de un sentido jurídico en la política y la oposición entre Dictadura y Estado de Derecho dieron sentido a la transición: la defensa de la vida, la ruptura con el pasado, la acción de la justicia y el ejercicio de la ley fueron los temas que atravesaron el horizonte simbólico del nuevo ciclo que se iniciaba (Sonderéguer, 2000: 2).

Sin embargo, esta modalidad canceló otros reclamos (entre ellos, la posibilidad de narrar la militancia social y política de la primera mitad de la década del setenta, como así también de destacar la responsabilidad de la sociedad civil respecto de la legitimación del régimen autoritario y represivo). Esto se debía, según lo analizaron numerosos trabajos en la temática, 
a cómo se resolvió la sanción jurídica al Terrorismo de Estado. Desde su inicio, la misma estuvo:

(...) ligada a un presupuesto que homologó la opción por violencia de los grupos políticos armados con la metodología represiva. De ese modo, desde la recuperación de la democracia, la violencia del gobierno militar fue explicada como resultado del accionar de dos sectores a los que se atribuyó la misma responsabilidad criminal: las organizaciones guerrilleras y las Fuerzas Armadas (Sondéreguer, 2000: 2).

Como destaca la historiadora Marina Franco (2014), en los primeros años de la posdictadura el tópico fundamental para explicar la violencia de los años setenta será pensarla como responsabilidad y resultado de dos fuerzas equivalentes enfrentadas y en una relación mutua de acción-reacción, a lo que, en reiteradas ocasiones, se sumará una sociedad civil representada como elemento exterior a (e incluso víctima de) esa violencia. Este esquema argumental binario es lo que corrientemente se denomina Teoría de los dos demonios (9), y constituye una de las mayores encrucijadas que operaron -y aún hoy operan- en los procesos de memoria. La metáfora demoníaca resulta una matriz de explicación simplificadora, insuficiente para captar la complejidad de la violencia setentista (sus raíces y ramificaciones históricas); uno de sus mayores peligros radica en que encubre la naturaleza diferente del terrorismo del estado, su cualidad de plan sistemático de exterminio de las fuerzas revolucionarias y su objetivo de normalización del conjunto social, ejercido de forma ilegal por parte de un gobierno de facto. Pero además, la visión de la sociedad civil que acarrea (en tanto ámbito situado por fuera de la voluntad de normalización autoritaria y víctima de un plan sistemático de exterminio que se ejercía a espaldas del conocimiento público), funciona como un velo de inocencia que disimula la responsabilidad de la sociedad civil en su condición de agente legitimador del régimen de facto y su accionar.

En este sentido, estas obras afirman para la contemporaneidad una imagen de la sociedad civil y el accionar mediático en el que se destacan las redes de connivencias, complicidades y pactos -tácitos y manifiestos- con el plan del gobierno militar. Articulan, así, modos de relectura crítica del período que han emergido en los últimos años en diversos campos del conocimiento histórico, y que discuten algunos de los supuestos fundamentales -originados en los primeros años de democracia- que organizan ciertas memorias aún vigentes: la idea de una sociedad que, desconocedora e ingenua, sería la principal damnificada de un período de la lucha entre fuerzas -así emparejadas- revolucionarias y reaccionarias. Se trata aquí de estrategias representativas del período que tendrían el potencial de abrir los horizontes de lo pensable y lo 
decible, a partir de un disparador estético que insta al presente a movilizarse y resignificar sus memorias cristalizadas.

\section{Reflexiones finales}

A lo largo de este trabajo, se han analizado dos obras de arte tecnológico contemporáneo que tematizan la desaparición forzada de personas durante la última dictadura cívico-militar haciendo uso de un motivo relativamente poco explorado en las poéticas de la memoria: el Mundial de 1978.

En ambas obras, se alude a un rol de los medios de comunicación como cómplices del régimen. Asimismo, discuten el sentido común de la inocencia de la sociedad civil en el período dictadura, corren el eje desde la visión de la víctima hacia la visión del responsable. En Desilusiones ópticas de Leo Núñez, existe una correspondencia entre la composición técnica y espacial de la obra y la organización del dispositivo mediático durante la dictadura: ambos operan desde el ocultamiento de la información para el espectador. Un sentido oculto, una realidad solapada, se proyecta sobre un espectador que es así sorprendido en el presente, en la misma postura festiva que la sociedad civil sostuvo durante el mundial mientras se cometían un genocidio. La propuesta conceptual del artista, entonces, si bien admite cierto grado de inocencia de la sociedad civil, también propicia un contenido moralizante que subraya una culpabilidad poco admitida, indica que la apatía, la distracción y la ignorancia son, finalmente (e incluso, nuevamente), modos de la complicidad.

Por su parte, en 1978-2003, Carlos Trilnick renueva una apuesta -que atraviesa toda su obra artística y propuesta pedagógica- por discutir los lenguajes audiovisuales hegemónicos: el cine comercial y la TV. En este caso, a un evento deportivo mediatizado como una fiesta colectiva y popular que legitimaba al régimen, el artista contrapone una obra sin cortes, sin efectos, sin trabajo de montaje, que registra el trayecto de un cuerpo que vela (literalmente, cubre con un velo negro) el arco donde se gritaron los goles. A una cancha de River insistentemente representada como espacio del triunfo, el artista contrapone su señalamiento como sitio de memoria.

Teniendo en cuenta que la memoria es siempre una construcción del presente dirigida a dar contenido a lo acontecido y a definir los conceptos con los que se lo piensa, estas obras resultan valiosos aportes para complejizar los procesos de anamnesis del pasado reciente y abrir en ellos nuevas líneas de sentido que, lejos de estar suturadas, continúan activas en el proceso de anamnesis (10).

Question, Vol. 1, N. ${ }^{\circ}$ 63, julio-septiembre 2019. ISSN 1669-6581

Instituto de Investigaciones en Comunicación | Facultad de Periodismo y Comunicación Social | Universidad Nacional de La Plata 


\section{Notas}

(1) La primera de ellas, se llevó a cabo en el Museo de Artes Visuales de la Universidad Nacional de Tres de Febrero (MUNTREF Caseros) y llevaba el subtítulo "Reflexiones sobre el horror a 30 años del golpe (1976-2006)". Constó de quince obras de dieciséis artistas (videos multicanal, videoesculturas, instalaciones interactivas e instalaciones electroacústicas) reunidos con el objetivo de meditar sobre la memoria de pasados traumáticos -en general- a través del arte tecnológico. La segunda edición, tuvo lugar en el marco de la III Bienal de la Imagen en Movimiento (BIM) que se desarrolló en el Centro de Arte Contemporáneo (CAC), sede Inmigrantes de MUNTREF. Esta versión constó de diez piezas de video monocanal de cuatro minutos cada una, comisionadas por la UNTREF a figuras destacadas del video nacional. De esta forma, la muestra dedicó cuarenta minutos en total a la reflexión audiovisual, un minuto por cada año transcurrido desde 1976.

(2) En pleno desarrollo del Mundial de fútbol, el diario francés Le Monde publica una carta abierta emitida a Videla en la que 2337 periodistas franceses pedían explicación por sus colegas argentinos asesinados, detenidos y desaparecidos. Según destaca Varela (2001) una estrategia para contrapesar este tipo de acusaciones se basó en utilizar el evento deportivo como pantalla para mostrar a la sociedad argentina y al mundo la capacidad de organización, el orden, la hospitalidad y la unión del pueblo argentino, como asimismo la legitimidad del gobierno militar.

(3) Tal era el uso de estas asociaciones que, como describe Roldán (2007), se llegó a vincular el tipo de juego que proponía el director técnico con el proyecto social y económico de la Junta: Menotti estableció un trabajo a largo plazo y de alta sistematicidad, y reivindicaba un "estilo" de juego que mixturara la "tradición" o "esencia" criolla, con la reivindicación del esfuerzo, la rigurosidad, el sacrificio; es decir, de la disciplina.

(4) Archetti (2004) reconstruye, citando una nota en diario Clarín y el testimonio de una de las sobrevivientes brindado al periodista Ezequiel Fernandez Moore, un escenario en el que los mismos prisioneros escuchaban la radio y se mostraron festivos el día de la victoria. Apela a una nota en Página 12 en la que el escritor y periodista Alfredo Leuco admite que, a pesar tener amigos desaparecidos, celebró el mundial; a otra nota de La Razón en la que un intelectual crítico como Ernesto Sábato hizo demostraciones públicas de felicidad. También el testimonio del activista político Claudio Tamburrini quien, habiendo huido de un centro de detención, no se privó de festejar en cada partido, e incluso el de Tati Almaida, una Madre de 
Plaza de Mayo que admite haber deseado tener a su hijo al lado para poder celebrar con él el triunfo.

(5) La descripción corresponde a la presentación de la obra en la sala 9 del Encuentro \#FASE Arte+Ciencia+Tecnología 6.0, que tuvo lugar en octubre de 2014 en el Centro Cultural Recoleta. La instalación fue también expuesta en Propaganda 2014, Barranquilla, Colombia, en septiembre de 2014 y en Futurissima/La sin Futuro, Buenos Aires, Argentina, en diciembre de 2013.

(6) La descripción corresponde a la instalación que se exhibió en Ejercicios de Memoria, 2006, MUNTREF Caseros I. La obra se expuso, además, en el Museo de la Memoria de Córdoba en 2010. Cabe destacar la ya aludida muestra en el Parque de la Memoria se organizó la muestra "Tiren Papelitos". En este caso, el video se encontraba proyectado en una de sala que contenía una tribuna; el espectador se podía sentar así para realizar el acto de recepción, como si estuviera en la cancha.

(7) La fiesta de todos, película de 1979 dirigida por Sergio Renán, de 110 minutos de duración.

(8) La dolorosa paradoja que plantea la cercanía entre la ESMA, donde funcionaba un centro de detención clandestino, y la cancha de River, sede del Mundial, es trabajada en obras como 1978 de Roberto Jacoby, en la que el artista interviene la sala principal del Centro Cultural de la Memoria Haroldo Conti con el murmullo de una cancha, reponiendo lo que habrían llegado a escuchar desde allí los detenidos.

(9) Cabe destacar que en este texto, la historiadora plantea que la "teoría de los dos demonios" es un objeto de estudio indeterminado, en tanto nunca ha sido formulada de forma sistemática como un corpus de ideas, ni reconocida como producto de un autor o promotor. Más bien, se trata de un "conjunto de representaciones colectivas, de amplia circulación, cuyas formulaciones más obvias cristalizaron en algunos enunciados públicos en los primeros años posdictatoriales. (...) Fue justamente en el proceso de su cuestionamiento y deconstrucción política que fue cristalizando y tomando entidad y existencia (...)" (Franco, 2014: 2).

(10) Este artículo es una versión corregida y ampliada de una ponencia presentada en las VI Jornadas Internacionales y IX Nacionales de Historia, Arte y Política organizadas por la UNICEN en 2018. Asimismo, el mismo surge del proceso de investigación de la tesis de Maestría en Curaduría en Artes Visuales (UNTREF) de la autora, defendida en mayo de 2019 y aún inédita.

\section{Bibliografía}


Archetti, E. P. (2004). El mundial de fútbol de 1978 en Argentina: victoria deportiva y derrota moral. Memoria y civilización, 7, pp. 175-194.

Avellaneda, A. (1986). Censura, autoritarismo y cultura: Argentina 1860-1983. Buenos Aires: Centro Editor de América Latina.

Borrelli, M. (2011). Voces y silencios: la prensa argentina durante la dictadura militar (19761983). Perspectivas de la Comunicación, 4(1), pp. 24-41.

Da Silva Catela, L. (2009). Lo invisible revelado. El uso de fotografías como (re) presentación de la desaparición de personas en Argentina. En Feld, C (Comp). El pasado que miramos. Memoria e imagen ante la historia reciente. Buenos Aires: Paidós.

Debray, R. (2007). Trasmitir más, comunicar menos. A Parte Rei 50. Revista de Filosofía, marzo. Recuperado de http://serbal.pntic.mec.es/ cmunoz11/debray50.pdf

Denegri, A. y Golder, G. (compiladores). (2007). Ejercicios de memoria. Reflexiones sobre el horror a 30 años del Golpe (1976-2006). Caseros: Eduntref.

Dubois, P. (2001). Video, Cine Godard. Buenos Aires: Libros del Rojas.

Feld, C. (2010). Imagen, memoria y desaparición. Una reflexión sobre los diversos soportes audiovisuales de la memoria. Aletheia, 1. Recuperado de https://bit.ly/2k8jkPS

Franco, M. (2007). Solidaridad internacional, exilio y dictadura en torno al Mundial de 1978. En Yankelevich, P. y Jensen, S. (compiladores). Exilios. Destinos y experiencias bajo la dictadura militar. Buenos Aires: Ediciones del Zorzal.

Franco, M. (2014). La 'teoría de los dos demonios': un símbolo de la posdictadura en la Argentina. A contra corriente, 11(2), winter, pp. 22-52.

Garretón Kreft, F.; González Le Saux, M. y Lauzán, S. (2011). Políticas públicas de verdad y memoria en 7 países de América Latina (Argentina, Bolivia, Brasil, Chile, Paraguay, Perú y Uruguay). Santiago: Universidad de Chile, Facultad de Derecho, Centro de Derechos Humanos.

Huyssen, A. (2002). Pretéritos presentes, medios, política, amnesia. En En busca del futuro perdido: cultura y memoria en tiempos de globalización. México: Fondo de Cultura Económica.

La Ferla, J. (comp). (2000). De la pantalla al arte transgénico. Buenos Aires: Libros del rojas.

La Ferla, J. (2009). Cine (y) digital. Aproximaciones a posibles convergencias entre el cinematógrafo y la computadora. Buenos Aires: Manantial.

Longoni, A. (2010). Fotos y siluetas: dos estrategias en la representación de los desaparecidos. En Crenzel, E. (comp.). Los desaparecidos en la Argentina. Memorias, representaciones e ideas (1983-2008). Buenos Aires: Biblos. 
Machado, A. (2000). El paisaje mediático. Sobre el desafío de las poéticas tecnológicas. Buenos Aires. Buenos Aires: Libros del Rojas.

Palmás Zaldua, L.; Torras, V.; Hourcade, S.; Blanchard, S. y Griffa, T. (2016). Las políticas de memoria, verdad y justicia a cuarenta años del golpe. En Cels (2016). Derechos Humanos en la Argentina. Informe 2016. Recuperado de http://www.cels.org.ar/especiales/informeanual2016/

Sonderéguer, M (2001). Los relatos sobre el pasado reciente en Argentina: una política de la memoria. Iberoamericana, 1(1). doi: http://dx.doi.org/10.18441/ibam.1.2001.1.99-112

Varela, M. (2001). Los medios de comunicación durante la dictadura. Silencio, mordaza y optimismo. Todo es Historia, 34, pp. 404. 